\title{
Foreign Aid Reduction and Local Civil Society: Recent Research and Policy Guidance for Donors and International NCOs
}

\author{
${ }^{1}$ School of Conflict Management, Kennesaw State University College of Humanities and Social Sciences, MD 1603, 1000 Chas- \\ tain Rd, Kennesaw, Ceorgia 30144, USA, E-mail: cpallas@kennesaw.edu. https://orcid.org/0000-0001-9323-7696. \\ ${ }^{2}$ School of Law, University of Wisconsin Madison, Madison, Wisconsin, USA, E-mail: mark.sidel@wisc.edu
}

\begin{abstract}
:
The impact of foreign aid reduction on local civil society organizations has gained a growing amount of scholarly attention over the past several years. However, most research has focused on the experiences of local CSOs and their adaptations to reduced donor support. In this piece, we review the extant literature to offer a comprehensive perspective on the role of donors in the aid reduction process. We highlight the ways that donor planning and management of aid reduction can enhance or undermine civil society sustainability and offer six prompts for donors, designed to improve the aid reduction process. These include inventorying donors' original development objectives; leaving behind an appropriate legal framework; facilitating local philanthropy; developing a framework for government support of CSOs; communicating aid reduction plans transparently; and supporting local adaptions to funding withdrawal.
\end{abstract}

Keywords: local civil society, foreign aid, donor exit

DOI: $10.1515 /$ npf-2019-0045

\section{Introduction}

In most developing country and post-conflict settings, donors have actively encouraged the growth of local civil society organizations (CSOs) and used them as implementing partners for donor programs. Local CSOs are often able to reach marginalized populations better than government actors and may be perceived as more efficient or less corrupt. Engagement with local CSOs can help democratize development by allowing some measure of local input and control over development projects. In some contexts, CSOs may also promote democracy and government accountability. Yet donor support for local civil society creates a dilemma. CSO reliance on donor aid threatens organizations' sustainability during periods of aid reduction and donor exit.

Over the last several years, the impact of foreign aid reduction on local CSOs has gained increasing attention from academics, policymakers, and donor and nongovernmental organization (NGO) staff. For example, the UK-based International NGO Training and Resource Centre (INTRAC) began working with major international NGOs (INGOs) on aid withdrawal and exit strategies in 2012 (INTRAC, n.d.). In 2015, the US Institute of Peace, in collaboration with Kennesaw State University and the US Army War College's Peacekeeping and Stability Operations Institute, hosted a multistakeholder workshop on the impacts of foreign aid reduction on local civil society in conflict and post-conflict states (Pallas 2016). In 2016, Development in Practice hosted a special issue on civil society sustainability that included multiple articles focused on funding changes (Pratt 2016). A special issue of VOLUNTAS: International Journal of Voluntary and Nonprofit Organizations, published in 2018, brought together studies of the impact of aid reduction on local CSOs from Eastern Europe, Central Asia, Latin America, Africa (Appe and Pallas 2018). A growing number of academic articles and practitioner reports in other venues also address this theme (e. g. Appe 2017; AFAO 2019).

What this research reveals is that the experience of aid reduction is relatively similar across regions and within both conflict affected and non-conflict affected states. The research published thus far highlights the challenges of aid reduction, including the curtailment of services to end beneficiaries and the loss of political protection from undemocratic or illiberal governments, but also notable opportunities that may result from aid reduction, including volunteer engagement, greater local autonomy, and new partnerships between local civil society and national governments (Arhin, Kumi, and Adam 2018; Pallas and Nguyen 2018). 
This new literature indicates that more positive outcomes can be produced by improving how donors and their INGO partners, who often administer donor aid programs at the country level, plan for aid reduction and communicate their intentions to local CSOs. Too often, however, opportunities for positive effects from aid reduction are lost due to an emphasis on short-term project goals or a seeming distrust on the part of international actors toward their local CSO counterparts. How then can donors and INGOs maximize civil society sustainability during periods of aid reduction?

In this article, we synthesize this new body of research to, hopefully, generate practical policy guidance for donors and INGOs with responsibility for planning for or managing aid reduction. Our goal is two-fold. First, we seek to prompt donors and INGOs to consider the effects of aid reduction in broad terms that go beyond amounts given or the number of individuals served by a particular project. Instead, we hope to help donors and INGOs to weigh more heavily the ways in which donor support for local CSOs builds societal infrastructure and lays a foundation for sustained action and services by communities. Second, we seek to outline some ideas for a planning process that incorporates an assessment of local resources and needs into exit planning and leverages collaboration and engagement with local stakeholders to improve the outcomes of the aid reduction process.

We argue that the interests of donors in supporting local CSOs often go far beyond CSOs' value as implementers of aid projects, and certainly should well exceed that. CSOs help inform donors of local needs and local social and political conditions (Balboa 2018). In conflict-affected states, they contribute to community organization and reduce violence (Cil and Aronson Under review). They support democratization and hold government leaders accountable (Robinson 1995). Indeed, supporting the growth of CSOs in order to foster such effects is often an implicit or explicit goal of donor support (Pallas and Nguyen 2018). Yet in the midst of planning and implementing exit strategies, international donors often emphasize completing the headline goals on the final projects - e. g. so many children vaccinated, so many clinics built - narrowing their focus to local CSOs' roles as subcontractors and aid implementers. In so doing, they may adopt exit strategies that undermine the long-term health and independence of local CSOs or undermine CSOs' ability to adapt to funding changes.

Proper planning for aid reduction and exit begins with an inventory of donor or INGO goals, reducing such project-focused tunnel vision. It continues by considering broadly what resources both donors and local CSOs bring to the table - not just money or human capital, but also political protection, access, or information. This sets the stage for developing an exit strategy that does more than just try to replace donor money (e. g. by shifting funding of CSOs from donors to the national government) or complete projects and instead considers how donors and CSOs can work together to create structures and practices that will sustain the CSOs and their services to end beneficiaries past the point of donor exit.

This article proceeds in three parts. It provides an overview of aid reduction as a global phenomenon and describes its observed impacts on local CSOs. It then proceeds to offer six suggestions for donor management of aid reduction, highlighting common challenges and recognized solutions. The article concludes with some reflections on the need for a proactive approach to planning for aid reduction.

\section{The Growing Scope of Aid Reduction}

As noted above, a number of articles have been published in the last five years describing the phenomenon of foreign aid reduction and identifying common themes in the way donors manage programmatic reduction, budget drawdowns and staff exit. This work highlights foreign aid reduction as a global phenomenon with notable impacts on local civil society and emphasizes the ways in which donors tend to manage exit, with limited attention to empowering local partners or preserving gains donors have made in developing or protecting local civil society.

Pallas, Anderson, and Sidel (2018) use World Bank data to examine instances of sustained decrease in the foreign aid to any given country between 1963 and 2013. They identify 539 instances of foreign aid reduction, including 328 cases in which foreign aid declined over six or more years. What these authors call aid reduction is typically modest, with a median decline of $21.9 \%$ over any given three-year period of decline (Pallas, Anderson, and Sidel 2018).

Significantly, though, the number of instances of foreign aid reduction are increasing. Pallas, Anderson, and Sidel (2018) note that while foreign aid is increasing overall, the total number of instances of foreign aid reduction are also increasing. This is consistent with the tendency of many donors to move funds away from middle income countries to focus on the smaller number of countries remaining at low income status. The Global Fund, for instance, requires that countries reaching middle income status contribute significantly more to their HIV / AIDS response than low income countries. As more countries enter middle income status, aid reduction is a growing issue for local CSOs and for the INGOs that work with them. Other motivations, such 
as rewarding states that move toward democracy or limit corruption, can also lead donors to concentrate their funds.

Aid reduction can be driven by other causes beyond middle income status and changing donor priorities. In some cases donors withdraw funds in response to development success. At the opposite end of the spectrum, donors may withdraw funds because they are fatigued by a lack of progress. In post-conflict and fragile states, aid funding may be reduced when renewed violence makes the country too dangerous for donor staff or because humanitarian intervention is more essential than development aid (Pallas 2016).

Not all foreign aid is accessible to local CSOs. Donors may provide direct budget support to the local government and may continue some support to the government even when reducing funding for development programming. Because of donor use of local CSOs as implementing partners in development aid programs, CSOs in countries experiencing general reductions in foreign aid report cuts to CSO funding.

It is clear that aid reduction has a notable effect on civil society regardless of its immediate cause. A growing number of case studies have appeared in the literature documenting the challenges such reduction poses. These include accounts from Latin America (Appe 2018); Europe (Heideman 2018; Nimu 2018); Central Asia (Bayalieva-Jailobaeva 2018); Africa (Arhin, Kumi, and Adam 2018; Krawczyk 2018; Pratt 2016); and Southeast Asia (Parks 2008; Pallas and Nguyen 2018). Other research has examined aid reduction from the perspective of INGOs (Hayman 2016) and in conflict-affected states (Pallas 2016). These sources record a variety of causes for aid reduction, ranging from donor fatigue to local politics to renewed violence, but find that regardless of the immediate cause of aid reduction, aid reduction poses an important set of challenges.

These challenges obviously include a loss of the project funding that supports services for stakeholder populations (Pallas and Nguyen 2018). Funding loss can also undermine organizational stability as local NGOs, many of which have adopted professionalized structures, sometimes in response to donor influence, lose the overheads that provide funding for their full-time staff (Nimu 2018; Arhin, Kumi, and Adam 2018). The loss of funding may push local CSOs to build closer relationships with the state (Arhin, Kumi, and Adam 2018). Foreign donors have often encouraged this process, in hopes that states, other donors, or private funding will preserve the development gains made by donor work through local NGOs (Bayalieva-Jailobaeva 2018; Heideman 2018). However, decreased donor funding and the exit of donor staff may also limit donors' influence over the government and expose local NGOs to increased government authority (Pallas and Nguyen 2018).

\section{Donor Management of Aid Reduction}

As noted, most of the research on aid reduction exists in the form of country-specific or regional case studies, complemented by some analysis of global trends in aid reduction. The main review piece in this area, Appe and Pallas (2018), focuses on the causes and consequences of aid reduction. Like the many case studies in this area, it emphasizes the impact on local CSOs.

In this article, however, we focus on the planning and implementation of exit strategies by international donors and the international NGOs that are often responsible for implementing donor aid programs. While planning for exit is a standard part of aid project proposals, such plans necessarily lack awareness of the future conditions, five or seven or ten years hence, when aid reduction will actually take place. When aid reduction finally happens, actual exit planning is typically hastily done, top-down, and poorly communicated with local partners (Vogus and Graff 2015; Pallas 2016; Appe and Pallas 2018). Significantly, such problems occur even in instances, such as a country rising to middle income status, where the cause of aid reduction can be anticipated and planned for well in advance. Yet when aid reduction is better planned and managed, the improved process yields better results (Heideman 2018; AFAO 2019). Thus we provide here some ideas for a roadmap, grounded in the recent literature, for improving the aid reduction process.

The steps described here are not strictly sequential and there is significant overlap in when these activities are conducted. Donors also operate on different funding cycles depending on their budgeting process and national or international politics. We note that work that requires local government cooperation should be begun before aid reduction is announced, at which point donors may lose significant political leverage. Ideally, donors will engage in some activities, like cultivating an enabling legal framework, throughout their work in a country, beginning even before aid reduction is planned.

Similarly, we assume that international donors will be the primary implementer of these activities. However, international NGOs acting as donor implementing agents will also have a key role. Local government and local CSOs may also participate when they have significant influence or knowledge to contribute. 


\section{Inventory Donor's Development Objectives}

In planning for aid reduction, the first step is often to make a comprehensive inventory of the donor's development objectives. Donors tend to focus on making or preserving gains in the core development metrics addressed by a given project or set of activities (Pallas and Nguyen 2018; Pratt 2016). As a result, the tendency of aid donors is to focus on funding replacement for local CSOs in a country or sector from which they are withdrawing aid and lose focus on other objectives, including civil society sustainability.

This can lead to a deliberate effort to steer local CSOs that have been involved in implementing donorfunded aid programs toward government funding and an explicit expectation that the national government will replace foreign donors as the primary funder for local civil society (Heideman 2018; Bayalieva-Jailobaeva 2018; Pallas and Nguyen 2018). Donor engagement with local NGOs around donor exit may also focus on improving local NGOs' access to other funders, and technical capacities such as grant writing ability, in the hope that one foreign donor will be replaced by others or that local NGOs will be able to tap into diversified funding sources or global funding pools even after funding specifically targeting their country has been reduced (Heideman 2018; AFAO 2019). Discussions with local NGOs may actually enhance this focus on funding replacement, as local NGO partners are likely to be professionalized organizations that have come to understand organizational operations and survival in terms of contracts, grants, and funding cycles. Yet this emphasis on cultivating relationships with donors may undermine CSO sustainability and limit CSOs' ability to pursue important activities, especially related to advocacy, that many donors are reluctant to fund (Pratt 2016; Parks 2008).

Moreover, it is important to recognize that professionalized CSOs are certainly not the sum of all local civil society (Fowler 2016). Preserving local civil society is itself an important objective. Just as donors actively seek to develop local civil society through their funding, donors must seek to preserve and protect it during their exit. A robust local civil society contributes to democracy, political participation, political stability, and economic development (Appe and Pallas 2018). The "social capital" created through the connections fostered by local civil society, along with the informal transfer of information among citizens, makes a significant contribution to national development. A healthy local civil society also creates infrastructure for future disbursements of foreign aid and for operationalizing growing domestic philanthropy. A strong community of local CSOs reduces the danger of rent-seeking and embezzlement by 'briefcase' NGOs created to profit from a sudden influx of donor cash and, in conflict-affected states, can ensure that aid does not exacerbate violence (Koch 2008; Cil and Aronson Under review).

Therefore, in planning for exit, donors must consider both the development metrics embedded in their various projects and their less quantifiable goals of developing local civil society. To the extent that donors have sought to develop legal protections for local civil society, build the capacity of local organizations, promote cooperation among local CSOs, or otherwise contribute to civil society sustainability, donors must consider how to preserve these goals. A comprehensive inventory must consider any and all of these goals and devise aid reduction or exit strategies that accommodate multiple objectives and give due priority to sustaining civil society once the support provided by aid is gone or significantly reduced.

\section{Leave an Appropriate Enabling Environment and Legal Framework for Civil Society}

Donor objectives in civil society engagement during project work may include developing legal recognition for their local civil society partners, in order to facilitate those partners' work and their collaboration with international donors and INGO partners, and an enabling environment for local civil society more generally. Donor presence and leverage can also play a key role in preventing government repression of local civil society, especially in less democratic states (Heideman 2018; Pallas and Nguyen 2018). In many cases, aid reduction decreases donor leverage over national government. Therefore, donors must seek to institutionalize government recognition of local CSOs and legal rights of assembly and association, and take steps as necessary to ensure that an enabling environment persists.

In recent years donors do appear to be paying more attention to these issues. The methods donors use to support civil society in the context of aid reduction are diverse, including conditioning tie-off and final grants or contracts on legalization of domestic CSO partners (if they have not been fully legalized before) and adoption of a facilitative enabling framework; providing enhanced, new or continuing support for developing a conducive enabling environment for domestic civil society and for continuing of foreign aid and philanthropy; helping local CSOs to explicitly raise issues of freedom of association and assembly and the enabling environment; 
enhancing support for capacity building in the enabling environment area so as to "leave behind" capacity to work on these issues; and other measures. Given the variety of political contexts in which donors operate, it is not possible to prescribe a single set of actions for all donors. Our key point is that donors should think through ways in which to facilitate a legal environment that is enabling for civil society; that there is no one way in which in which to do that and that interventions in this area should be both diverse and tailored to local needs; and that if possible multiple, diversified and dynamic ways should be sought to achieve these objectives, both at the time of aid reduction and in the years that follow.

\section{Facilitating Local Philanthropy}

In many of the instances observed in the literature, donors reduce aid and withdraw staff due to a country's relative success in economic development or post-conflict reconstruction. As a country rises to middle-income status, it develops a deeper pool of local resources, including a rising middle class and wealthy entrepreneurs, who are capable of supporting civil society activities though domestic funding and philanthropy (Pandya and Ron 2017; To 2016). Yet donors often persist in their established pattern of government and foundation funding for local civil society, creating exit strategies that focus on substituting government funds or new international grants for the funds donors withdraw (AFAO 2019; Heideman 2018). Yet to build a sustainable and independent civil society, donors must look to facilitate local philanthropic giving, whether from private individuals, local foundations, or corporations.

These days, many donors do that. In the past decade, most donors engaged in aid withdrawal have sought to think beyond substituting government funds or new international funds for aid reduction. But progress in this area is slow. The dynamics of the growth of local funding availability - of domestic family and business philanthropy and individual giving and other sometimes newer forms of giving - are often not well understood and are developing rapidly on the ground. Even where the government seeks to facilitate local giving, CSOs may be reluctant to pursue it, in part because of low fundraising capacity (Hu and Guo 2016). So in many cases it doesn't make sense for donors to try to "predict" developments in a rapidly changing local resource environment, and predicate specific departure decisions and programming on such data. Instead, what makes more sense is helping to foster local institutions and capacity that can themselves track these developments and be adaptive and flexible and facilitative to a local resource environment that will virtually certainly look very different ten or even five years after aid reduction than it does at the moment when final grants and contracts are being issued (Holloway 2001; Merz, Chen, and Geithner 2007).

\section{Building a Framework for National Government Support}

In cases where the national government is likely to take over donor aid programs currently implemented via local CSOs or to otherwise fund local civil society, donors should consider how to proactively build a framework for that relationship that acknowledges local government interests while still cultivating CSOs' independence and sustainability. This includes both preserving CSOs' ability to act as service providers, especially to marginalized populations, and preserving CSOs' freedom to undertake advocacy.

Donors often believe that they must work with national governments to develop funding mechanisms that respect civil society independence while preserving a necessary focus on key communities and populations. They are justified in doing so, and they do that on the basis that private giving alone, at least over the shortterm, is unlikely to be a complete substitute for donor funds. Indeed, data from a multi-country study on the HIV / AIDS sector indicates that private donors often explicitly structure or earmark their funds to avoid controversial issues or populations (Tanguay 2017). At the same time, foreign donors - often for political reasons of their own - often continue some measure of giving to the national government. Thus, donors routinely expect local civil society to receive substantial funding from the national government to continue the development efforts donors have supported (Bayalieva-Jailobaeva 2018; Heideman 2018; Pallas and Nguyen 2018; AFAO 2019).

The literature suggests that national government funding for civil society activities can have quite disparate effects on local civil society and on project beneficiaries. When government funding is readily accessible and respects some measure of civil society independence, as seen in Poland and Croatia, such systems can increase the health of local civil society and ensure service provision to beneficiary populations (Nimu 2018; Heideman 2018). When funding is inaccessible or the government is hostile to certain beneficiary populations, this strategy can undermine civil society sustainability and inhibit effective service provision (Bayalieva-Jailobaeva 2018).

The case of Thailand reflects both of these dynamics. A relatively good relationship between the Thai government and civil society has led to CSOs receiving government funding to address the HIV / AIDS epidemic in 
certain marginalized and hard-to-reach key populations (Bogner 2015). However, because of government antipathy toward migrant populations, CSOs receive no government funding for working with migrants, despite the important role this population plays in Thailand's epidemic (Avert 2018). India also reflects these dynamics. As donor activity wanes, and as grant activity from private providers such as the Ford Foundation and other foreign funders is under significant pressure over a number of years, the funding available from New Delhi or from subnational governments becomes more important. And yet that funding is highly targeted toward projects, communities and populations that the state supports, and not toward other groups; not nearly as diverse in its interests as some foreign aid support and most foreign foundation support. When the state substitutes for external official and unofficial funding, funding narrows.

In planning for funding hand-over, donors should consider both the structure of government mechanisms and CSOs' capacity to access them. Funding mechanisms must be accessible and funding should not be awarded in such a way that pursuing or accepting government support prohibits CSOs from advocating for changes in government policies where necessary (Tanguay 2017; AFAO 2019). This is particularly important given that a key function of local CSOs may be to advocate for additional government funding for marginalized issues or populations (AFAO 2019; cf. Heideman 2018). Establishing consultative bodies in which CSOs and government collaborate in setting funding priorities, as has been done in Croatia and Malaysia, may mitigate the tendency of government funding to focus on the programs, projects and viewpoints supported by the government (Tanguay 2017; Heideman 2018).

At the same time, CSOs must have sufficient capacity to access funding mechanisms, including meeting funding and reporting requirements. One key goal is to ensure that access to domestic funding is not limited to a small number of elite organizations. Transition planning can help build CSO technical capacity to apply for funding (Heideman 2018). Mapping national and subnational funding sources and conveying this information to local CSOs can also be a key part of transition planning (AFAO 2019). If receipt of government funding is contingent on organizations being properly registered with the government, transition plans may include efforts to help more local CSOs become appropriately registered or accredited (AFAO 2019).

\section{Communicate with Local CSOs}

Donor plans for aid reduction need to be communicated as transparently and as early as possible to local CSOs so that local CSOs can provide feedback on donor plans and undertake their own preparations for aid reduction. In many countries, donor plans are implemented through a large international NGO contracted for that purpose. These international NGOs often have significant responsibility for designing programs and for subcontracting with local CSOs. Thus, they often communicate donor intentions and objectives to local counterparts. Where donors work via INGO intermediaries, donors must ensure that INGOs pass aid reduction information on to local partners. Even though donors are consulting with local civil society during planning processes far more now than perhaps two or three decades ago, one of the consistent themes across the literature on aid reduction - and in complaints from local CSOs - is that aid reduction is frequently planned without significant consultation with local partners (Hayman 2016; Krawczyk 2018; Pallas and Nguyen 2018; Tanguay 2017). Moreover, donor decisions are often communicated poorly, with donors and INGO intermediaries sharing only limited information with local partners about exit strategies and timelines (Vogus and Graff 2015). In fact, donors may deliberately withhold information out of a fear that local partners will divert funds away from project objectives to protect their organizations' survival or enrich their staff (Pallas 2016).

While the decision to reduce aid rests almost entirely with the aid donor, local CSOs can offer valuable insights into how aid reduction can be best managed and the steps donors can take to ensure greater civil society sustainability. Local CSOs know the local terrain. They typically have important insights into the needs of beneficiary population and can offer an alternative perspective on the government's relationship with local civil society. Thus, they can help with the framing process described above. Moreover, local CSOs have the best understanding of their own capacity to adapt. Their knowledge of the local terrain can allow them to consider opportunities, such as offering fees for services or developing social enterprises, that outsiders may be unable to recognize or reluctant to embrace (Pratt 2016; Pallas and Nguyen 2018). Yet seizing such opportunities may yield a more sustainable local civil society than simply redirecting local CSOs to alternative donors.

In short, it is crucial for aid providers to work with local civil society and to invite local input - especially when entering final funding cycles. Aid providers should not use communication as a means of controlling local organizational behavior. A daring donor might ask key beneficiaries, "What have you not liked about working with us? What would you have done differently if you had greater freedom/less pressure? What is valuable to do going forward in a changed aid environment?" and then develop an exit strategy that uses the tail-end of funding to help launch local CSOs on a locally-charted course. 


\section{Support Local Adaptation}

Local civil society can adapt to lower funding environments, but that process takes time, and its results are hard to predict. $100 \%$ funding replacement may not be needed. Some organizations may somewhat deprofessionalize and replace paid staff with volunteers (particularly if their earlier professionalization was in part due to donor mandates) and some costs of intervention can be borne by beneficiaries or by fundraising from indigenous donors (Pallas and Nguyen 2018). Heideman (2018) notes that developing revenue generating activities can support civil society sustainability. Collaboration, especially technical assistance, between local CSOs can also replace some donor interventions (Heideman 2018; Appe 2018).

Donors can encourage this transition. Evidence indicates that changes in the government's fundraising policies can begin to change local NGOs' fundraising opportunities (Hu and Guo 2016). The Global Fund-financed SHIFT program, implemented across four Southeast Asian countries, had notable success in facilitating CSOs' efforts to engage in domestic advocacy around sustainable financing (AFAO 2019). USAID's 'legacy mechanisms' in Croatia enhanced CSO sustainability by improving CSO technical capacity, facilitating cooperation among CSOs, and encouraging the development of revenue-generating activities (Heideman 2018). Financingrelated reforms, like tax exemption for not-for-profit commercial activities, can be included alongside other the donor efforts at legal reform described above, such as legal recognition for local CSOs (Heideman 2018; AFAO 2019).

\section{Conclusion}

As more countries transition into middle-income status or post-conflict stability, more donors are facing the challenge of planning for funding withdrawal and donor exit. Such withdrawal directly impacts local CSOs and, via those impacts, affects the sustainability of donor goals for political and economic development. This short article hopes to help donors in thinking about the longer-term, difficult issues that arise as they reduce their aid and depart.

The recent wealth of case studies and other research on funding transitions provides ample data on what can go wrong during aid reduction - but also what can go right. Aid reduction often suffers from short-sighted planning, limited local consultation, and an over-reliance on replacing foreign funding with domestic government funding without appropriate attention to local legal and political conditions. Yet some donors have done an admirable job of planning for transition in collaboration with local CSOs or implementing transition programs designed to enhance civil society sustainability (Heideman 2018; AFAO 2019). These successes indicate that local CSOs, with donor support, can effectively advocate for necessary changes in the local funding environment, develop alternative funding streams, and build collaborative practices. In these cases, the resulting civil society sector is actually more resilient and sustainable than at the height of foreign donor support. Thus, donors should ask not just "What harm might we do by withdrawing?" but also "What good can we do in withdrawing?" and "How can we enhance local civil society's effectiveness through the tools and resources we leave behind?"

\section{References}

AFAO. 2019. Sustainable HIV Financing in Transition (SHIFT) Endline Evaluation Report. Australian Federation of HIV/AIDS Organizations. Online at: https://www.afao.org.au/wp-content/uploads/2019/05/SHIFT-Endline-Evaluation-Report.pdf/Accessed 6 Jan 2020.

Appe, S. 2017. “Civil Society Organizations in a Post-Aid World: New Trends and Observations from the Andean Region." Public Administration and Development 37(2): 122-35.

Appe, S. 2018. "Directions in a Post-Aid World? South-South Development Cooperation and CSOs in Latin America." VOLUNTAS: International Journal of Voluntary and Nonprofit Organizations 29(2): 271-83.

Appe, S., and C. L. Pallas. 2018. “Aid Reduction and Local Civil Society: Causes, Comparisons, and Consequences.” VOLUNTAS: International Journal of Voluntary and Nonprofit Organizations 29(2): 245-55.

Arhin, A. A., E. Kumi, and M. A. S. Adam. 2018. “Facing the Bullet? Non-Covernmental Organisations' (NCOs') Responses to the Changing Aid Landscape in Chana." VOLUNTAS: International Journal of Voluntary and Nonprofit Organizations 29(2): 348-60.

Avert. 2018. "HIV and AIDS in Thailand." Online at: https://www.avert.org/professionals/hiv-around-world/asiapacific/thailand\#footnote29_f8nztz7. Accessed 8 July 2019.

Balboa, C. M. 2018. The Paradox of Scale: How NCOs Build, Maintain, and Lose Authority in Environmental Covernance. Cambridge: MIT Press. Bayalieva-Jailobaeva, K. 2018. “New Donor Strategies: Implications for NCOs in Post-Soviet Kyrgyzstan.” VOLUNTAS: International Journal of Voluntary and Nonprofit Organizations 29(2): 284-95. 
Bogner, M. 16 September 2015. “Civil Society Space Shrinks in South-East Asia." In Myanmar Times, Online at: http://www.mmtimes.com/index.php/opinion/16491-civil-society-space-shrinks-in-south-east-asia.html. Accessed 8 July 2019.

Cil, D., and J. Aronson. Under review. Local Ownership of Aid: Reconstruction Assistance, Effective Counterparties, and Insurgent Violence. Fowler, A. 2016. “Non-Covernmental Development Organisations' Sustainability, Partnership, and Resourcing: Futuristic Reflections on a Problematic Trialogue." Development in Practice 26(5): 569-79.

Hayman, R. 2016. “Unpacking Civil Society Sustainability: Looking Back, Broader, Deeper, Forward.” Development in Practice 26(5): 670-80.

Heideman, L. J. 2018. "Making Civil Society Sustainable: The Legacy of USAID in Croatia." VOLUNTAS: International Journal of Voluntary and Nonprofit Organizations 29(2): 333-47.

Holloway, R. 2001. Towards Financial Self-Reliance: A Handbook on Resource Mobilization for Civil Society Organizations in the South. London: Earthscan.

$\mathrm{Hu}$, M., and C. Guo. 2016. "Fundraising Policy Reform and Its Impact on Nonprofits in China: A View from the Trenches." Nonprofit Policy Forum 7, no. 2 (June): 213-36.

INTRAC. Undated. "Aid Withdrawal and Exit Strategies." Available at: https://www.intrac.org/projects/aid-withdrawal-exit-strategies/ Accessed 16 May 2019.

Koch, D. J. 2008. “A Paris Declaration for NCOs?” In OECD Financing for Development 2008: Whose Ownership? Paris: OECD Publishing.

Krawczyk, K. 2018. “The Relationship between Liberian CSOs and International Donor Funding: Boon or Bane?” VOLUNTAS: International Journal of Voluntary and Nonprofit Organizations 29(2): 296-309.

Merz, B., L. Chen, and P. Ceithner. 2007. Diasporas and Development. Cambridge. Boston, MA: Clobal Equity Initiative, Harvard University.

Nimu, A. 2018. "Surviving Mechanisms and Strategies of Gender Equality NGOs in Romania and Poland." VOLUNTAS: International Journal of Voluntary and Nonprofit Organizations 29(2): 310-32.

Pallas, C., Q. Anderson, and M. Sidel. 2018. “Defining the Scope of Aid Reduction and Its Challenges for Civil Society Organizations: Laying the Foundation for New Theory." VOLUNTAS: International Journal of Voluntary and Nonprofit Organizations 29(2): 256-70.

Pallas, C. L. 2016. "Aid Reduction and Local Civil Society in Conflict-Affected States: New Research and Stakeholder Dialogue." Journal of Peacebuilding \& Development 11(1): 105-09.

Pallas, C. L., and L. Nguyen. 2018. “Donor Withdrawal and Local Civil Society Organizations: an Analysis of the HIV/AIDS Sector in Vietnam.” Development Policy Review 36(1): 131-51.

Pandya, A., and J. Ron. 2017. “Local Resources for Local Rights? The Mumbai Fundraiser's Dilemma.” Journal of Human Rights 16(3): 370-87.

Parks, T. 2008. "The Rise and Fall of Donor Funding for Advocacy NCOs: Understanding the Impact." Development in Practice 18(2): $213-22$.

Pratt, B. 2016. "Special Issue Overview: Civil Society Sustainability." Development in Practice 26(5): 527-31.

Robinson, M. 1995. "Strengthening Civil Society in Africa: The Role of Foreign Political Aid." IDS Bulletin 26(2): 70-80.

Tanguay, P. 2017. Baseline Assessment of Sustainable HIV Financing for HIV CSOs in Indonesia, Malaysia, Philippines and Thailand. Australian Federation of AIDS Organisations.

To, Linda. 20 January 2016. “Cetting Creative with Local Resource Mobilization in Hong Kong.” In openDemocracy, Online at: https://www.opendemocracy.net/openglobalrights/linda-to/getting-creative-with-local-resource-mobilization-in-hongkong/. Accessed 11 July 2019.

Vogus, A., and K. Graff. 2015. “PEPFAR Transitions to Country Ownership: Review of past Donor Transitions and Applications of Lessons Learned to the Eastern Caribbean." Clobal Health: Science and Practice 3(2): 274-86. 